\title{
Avaliação de substratos de floresta tropical para cultivo e produção de proteases por Pleurotus djamor
}

\author{
Evaluation of tropical forest substrates for cultivation and production of proteases by Pleurotus \\ djamor
}

Evaluación de sustratos de bosque tropical para cultivo y producción de proteasas de Pleurotus djamor

\section{Resumo}

Cogumelos do gênero Pleurotus são cultivados para fins alimentícios, medicinais e por serem fontes de enzimas de interesse industrial. $\mathrm{O}$ presente estudo teve como objetivo avaliar o crescimento micelial e verificar a atividade de proteases de $P$. djamor. Este cogumelo foi cultivado em ágar batata dextrose (BDA) com extrato de levedura (YE) $0,5 \%(\mathrm{p} / \mathrm{v})$. Para avaliar a velocidade do crescimento micelial radial (VCR) e densidade micelial, P. djamor foi cultivado em cinco meios com YE 0,5\% (p/v): ágar batata dextrose (BDA+YE), ágar Sabouraud (SAB+YE), ágar extrato de malte (MEA+YE), ágar inhame-roxo (PYA+YE) e ágar cará-de-espinho (SYA+YE). A atividade proteolítica foi determinada pelo método de bloco de gelose. Na avaliação do crescimento micelial vertical (VCM) foram utilizados exocarpos de cupuaçu (CE) e abacaxi (PE), semente de açaí (AS) e serragem (SAW), suplementados com farelo de arroz (RB) ou farelo de trigo (WB). A VCR significativa foi observada em SYA+YE $(11,26 \mathrm{~mm} / \mathrm{dia}) \mathrm{e}$ PYA+YE $(10,97 \mathrm{~mm} / \mathrm{dia})$. Porém, SAB+YE favoreceu a densidade micelial, portanto foi o meio selecionado para obtenção de inóculo nos testes de avaliação do crescimento micelial de $P$. djamor em resíduos lignocelulósicos. Atividade proteolítica significativa foi determinada em BDA+YE (17,7 mm), MEA+YE (17,6 mm) e SAB+YE (17,0 $\mathrm{mm})$. Forte densidade micelial e VCM significativa foi determinada em CE+WB $(0,37 \mathrm{~cm} / \mathrm{dia})$ e $\mathrm{CE}+\mathrm{RB}(0,30$ $\mathrm{cm} /$ dia). Substratos de floresta tropical são eficientes para o cultivo micelial e produção de proteases por $P$. djamor.

Palavras-chave: Amazônia; Cogumelo comestível; Enzimas; Resíduo lignocelulósico. 


\begin{abstract}
Mushrooms of the genus Pleurotus are cultivated as food, for medicinal purposes and also because they are sources of enzymes of industrial interest. The present study aimed to evaluate mycelial growth and verify the activity of $P$. djamor proteases. This mushroom was grown on potato dextrose agar (BDA) with yeast extract (YE) $0.5 \%$ (w/v). In order to evaluate the speed of radial mycelial growth (VCR) and mycelial density, $P$. djamor was grown in five media with $0.5 \%$ YE (w/v): potato dextrose agar $(B D A+Y E)$, Sabouraud agar $(\mathrm{SAB}+\mathrm{YE})$, malt extract agar $(\mathrm{MEA}+\mathrm{YE})$, purple yam agar (PYA+YE) and cará-de-espinho agar (SYA+YE). Proteolytic activity was determined by the agar block method. For the vertical mycelial growth evaluation (VCM), cupuaçu (CE) and pineapple (PE), açaí seed (AS) and sawdust (SAW) exocarps were used, supplemented with rice bran (RB) or wheat bran (WB). Significant VCR was observed in SYA+YE (11.26 mm / day) and PYA+YE (10.97 mm / day). However, SAB+YE favored mycelial density, so it was the medium selected for obtaining inoculum for the tests to evaluate mycelial growth of $P$. djamor in lignocellulosic residues. Significant proteolytic activity was determined in BDA+YE (17.7 mm), MEA+YE (17.6 $\mathrm{mm})$ and $\mathrm{SAB}+\mathrm{YE}(17.0 \mathrm{~mm})$. Strong mycelial density and significant CMV was determined in CE+WB $(0.37 \mathrm{~cm} /$ day) and $\mathrm{CE}+\mathrm{RB}(0.30 \mathrm{~cm} /$ day $)$. Rainforest substrates are efficient for mycelial cultivation and protease production by $P$. djamor.
\end{abstract}

Keywords: Amazon; Edible mushroom; Enzymes; Lignocellulosic residue.

\title{
Resumen
}

Hongos del género Pleurotus son cultivados para fines alimenticios, medicinales y por ser fuentes de enzimas de interés industrial. El presente estudio tuvo como objetivo evaluar el crecimiento micelial y verificar la actividad de proteasas de $P$. djamor. Este hongo se cultivó en agar papa dextrosa (APD) con extracto de levadura (EL) 0.5\% (p/v). Para evaluar la velocidad de crecimiento micelial radial (VCMR) y la densidad micelial, $P$. djamor fue cultivado en cinco medios con EL 0.5\% (p/v): agar papa dextrosa (APD+EL), agar Sabouraud (AS+LE), agar extracto de malta (AEM+EL), agar ñame morado (AÑM+EL) e agar cará espinoso (ACE+EL). La actividad proteolítica se determinó por el método del bloque de gelosa. En la evaluación del crecimiento micelial vertical (CMV) fueron utilizados exocarpos de copoazú (EC) y piña (EP), semilla de asaí (SA) y aserrín (A), suplementados con salvado de arroz (SA) o salvado de trigo (ST). La VCMR resultó ser significativa en ACE+EL (11.26 mm/dia) y AÑ +EL (10.97 mm/dia). Sin embargo, AS+EL favoreció la densidad micelial, siendo el medio seleccionado para la obtención de inóculo en las pruebas de evaluación del crecimiento micelial de $P$. djamor en resíduos lignocelulósicos. Por otra parte, la actividad proteolítica demostró significancia en APD+EL (17.7 mm), AEM+EL (17.6 mm) y AS+EL (17.0 mm). Finalmente, una fuerte densidad micelial y CMV significativa fue evidenciada en EC+ST $(0.37 \mathrm{~cm} / \mathrm{dia})$ y EC+SA $(0.30 \mathrm{~cm} / \mathrm{dia})$. Así, los sustratos de bosque tropical son eficientes para el cultivo micelial y producción de proteasas por $P$. djamor.

Palabras clave: Amazonia; Hongo comestible; Enzimas; Residuo lignocelulósico.

\section{Introdução}

Cogumelos do gênero Pleurotus (Jacq.: Fr.) Kumm têm propriedades terapêuticas, características sensoriais atrativas, valor nutricional relevante e continua como a segunda espécie de macrofungo comestível mais distribuída mundialmente (Balan et al., 2018; Putzke \& Putzke, 2019; Sekan, Myronycheva, Karlsson, Grygansky, \& Blume, 2019). Na Região Norte brasileira, diversos estudos vêm sendo desenvolvidos para adequar métodos de cultivo de espécies de Pleurotus visando à comercialização e à elaboração de bioprodutos, além de incentivar o consumo de alimentos saudáveis pela população (Machado, Teixeira, Kirsch, Campelo, \& Oliveira, 2016; Souza et al., 2016).

Pleurotus djamor (Fr.) Boedijn está classificado na família Pleurotaceae, ordem Agaricales (Oropeza-Guerrero et al., 2018; Raman, Hariprasath, Jang, Vikineswary, \& Nanjian, 2018). Esta espécie comestível, também denominada de cogumelo ostra rosa ou salmão, possui basidiomas grandes, com coloração atraente e sabor agradável. Além disso, pode ser cultivado em faixa ampla de temperatura $\left(26{ }^{\circ} \mathrm{C}\right.$ a $\left.35{ }^{\circ} \mathrm{C}\right)$ e umidade ambiental superior a $80 \%$ (Jegadeesh, Lakshmanan, Kab-Yeul, Sabaratnam, \& Raaman, 2018).

Nos últimos anos, pesquisas têm demonstrado que $P$. djamor tem potencial para aplicações biotecnológica e medicinal, além de ser alimento orgânico (Ragasa et al., 2016; Sudha et al., 2016). As características físicas, sensoriais e fisiológicas, além do consumo crescente de $P$. djamor, tem estimulado a realização de investigação com a finalidade de avaliar a adaptação dessa espécie em substratos alternativos para crescimento e produção de basidiomas (Satpal et al., 2017). A avaliação de substratos que promovam rápida e vigorosa colonização micelial é importante para selecionar materiais lignocelulósicos que proporcionem a produção significativa de cogumelos (Carrasco-González, Serna-Saldívar, \& Gutiérrez- 
Uribe, 2017; Barh et al., 2019).

Fonseca, Silva, Alecrim, Cruz e Teixeira (2015) e Machado et al. (2016) citaram que resíduos lignocelulósicos da floresta amazônica constituem uma alternativa biotecnológica para cultivo e produção significativa de proteases por $P$. ostreatoroseus, contudo não há relatos na literatura para P. djamor.

Outras enzimas também são produzidas por representantes do gênero Pleurotus, como celulases, amilases, entre outras (Devi et al., 2020). Destes biocatalisadores, predominam as proteases, que representam mais de $70 \%$ do mercado mundial e são utilizadas numa diversidade de processos industriais, com destaque para a produção de alimentos, medicamentos e detergentes (Benmrad et al., 2019). O objetivo desta investigação foi avaliar fontes nutricionais orgânicas oriundas de floresta tropical para crescimento de $P$. djamor e a produção de proteases extracelulares como substratos alternativos para cultivo de cogumelos em área tropical.

\section{Metodologia}

\subsection{Cogumelo}

Nesta pesquisa foi utilizado P. djamor DPUA 1818, cedido pelo acervo da coleção de culturas DPUA do Departamento de Parasitologia, da Universidade Federal do Amazonas. Para obtenção da forma micelial foi inoculado o fragmento de micélio em Ágar Batata Dextrose (BDA), suplementado com 0,5 \% (p/v) de extrato de levedura (YE). De cada cultura pura e viável, em triplicata, foi transferido disco micelial de $10 \mathrm{~mm}$ de diâmetro para ágar BDA+YE em placas Petri (100 mm x $15 \mathrm{~mm}$ ). Os cultivos foram mantidos a $25^{\circ} \mathrm{C}$ na ausência de luz, por oito dias para uso nos demais experimentos (Fonseca et al., 2015).

\subsection{Crescimento Micelial Radial}

O crescimento micelial radial foi avaliado em cinco meios de cultura adicionados de YE 0,5\% (p/v): (1) ágar batata dextrose + YE (BDA+YE), (2) ágar Sabouraud + YE (SAB+YE), (3) ágar extrato de malte + YE (MEA+YE), (4) ágar inhameroxo (Dioscorea alata) + YE (PYA+YE) e (5) ágar cará-de-espinho (Dioscorea altissima) + YE (SYA+YE). Em cada meio, contido placa de Petri, foi inoculado um disco micelial de $10 \mathrm{~mm}$ de diâmetro. As culturas foram mantidas a $28{ }^{\circ} \mathrm{C}$ por 8 dias, na ausência de luz. O crescimento de $P$. djamor foi analisado em milímetros, medindo o diâmetro da colônia em sentidos diametralmente opostos, utilizando uma régua graduada, a cada 24 horas por oito dias. Todos os experimentos foram realizados em quintuplicata, segundo as recomendações de Castillo (2009). A velocidade de crescimento radial (VCR) foi determinada conforme Equação I:

\section{Equação I: VCR $=\frac{\text { diammatro colônia (mm) }}{\text { Tempo de cultivo (dias) }}$}

A densidade do micélio, com base no vigor micelial de P. djamor, foi o critério utilizado para selecionar o meio de cultura para crescimento radial desse cogumelo. A avaliação do vigor micelial de cada cultura foi classificada pelo método subjetivo de notas: nota 1 (fracamente adensado); nota 2 (mediamente adensado); e nota 3 (fortemente adensado), conforme classificação citada por Marino, Abreu, Mesquita e Ribeiro (2008).

\subsection{Efeito da composição do meio de cultura na produção de proteases}

Para avaliar a atividade de proteases de P. djamor foram utilizados discos miceliais das culturas obtidas em cinco meios. A atividade proteolítica foi determinada em meio sólido pelo método de bloco de gelose. De cada cultura foram retirados discos miceliais de $10 \mathrm{~mm}$ de diâmetro e inoculados na superfície de ágar leite $5 \%$ (p/v), em placa de Petri. As placas 
foram mantidas a $37^{\circ} \mathrm{C}$. Após 18 horas foi determinada a atividade de proteases, medindo o diâmetro do halo em milímetros (Teixeira, Silva, Palheta, Carneiro, \& Ataíde, 2011). Os testes foram realizados em sextuplicata.

\section{4 Crescimento micelial vertical em Resíduos Lignocelulósicos}

\subsubsection{Resíduos Lignocelulósicos}

$\mathrm{Na}$ avaliação do crescimento micelial vertical foram utilizados os resíduos lignocelulósicos da fruticultura amazônica e serragem: (1) exocarpo de cupuaçu (Theobroma grandiflorum Schum) - CE, (2) semente de açaí (Euterpe oleracea) - AS, (3) serragem - SAW e (4) exocarpo de abacaxi (Ananas comosus) - PE. Cada resíduo foi suplementado com farelo de arroz - RB ou farelo de trigo - WB, separadamente.

\subsubsection{Tratamento dos Resíduos Lignocelulósicos}

Os resíduos foram lavados em água corrente para retirada do excesso de sujeira, em seguida, higienizados com solução desinfetante para hortifrutícolas contendo cloro ativo $0,85 \%(\mathrm{p} / \mathrm{p})$. Após 15 minutos foram submetidos à lavagem sucessiva, seguindo a drenagem do excesso de líquido. Cada resíduo foi misturado com RB ou WB e a umidade e o pH aferidos para $60 \%$ e 6,0, respectivamente. Os substratos foram acondicionados em tubos de ensaio (200 $\mathrm{mm} \times 25 \mathrm{~mm}$ ) contendo na sua base algodão umedecido com água destilada, formando uma coluna de $15 \mathrm{~cm}$ (Palheta, Vieira, Neves, \& Teixeira, 2011). Os tubos contendo as misturas de resíduos foram esterilizados a $121{ }^{\circ} \mathrm{C}$, durante 60 minutos, por três dias consecutivos, procedendo ao resfriamento por 24 horas. Em cada tubo foi afixado externamente três fitas milimetradas (130 $\mathrm{mm} \times 10 \mathrm{~mm})$.

\subsubsection{Inóculo}

Para a obtenção do inóculo, da cultura estoque de $P$. djamor foi retirado um disco micelial de $10 \mathrm{~mm}$ e transferido para superfície do meio sólido selecionado com base no vigor micelial, em experimento anterior. Os cultivos em placas Petri (100 mm x $15 \mathrm{~mm}$ ) foram mantidos a $25^{\circ} \mathrm{C}$, na ausência de luz por oito dias (Palheta et al., 2011).

\subsubsection{Cultivo de P. djamor em Resíduo Lignocelulósico}

Da cultura inóculo foram retirados três discos miceliais de $10 \mathrm{~mm}$ de diâmetro e transferidos para superfície dos substratos lignocelulósicos (item 2.4.1), em tubo de ensaio de (200 mm x $25 \mathrm{~mm}$ ). Nesses cultivos mantidos a $28{ }^{\circ} \mathrm{C}$, na ausência de luz, o crescimento micelial vertical e a velocidade de miceliação foram observados a cada 24 horas por 15 dias consecutivos. Todos os experimentos foram realizados em triplicata. A velocidade do crescimento micelial vertical (VCM) foi determinada em milímetros, de acordo com a equação II (Israel, 2005; Palheta et al., 2011). A avaliação do vigor micelial foi realizado método subjetivo descrito por Marino et al. (2008).

\section{Equação II: VCM $=\frac{V f-V i}{\text { Tf }}$}

Onde:

VCM = Velocidade média do crescimento micelial ao dia;

$\mathrm{Vf}=$ medida do crescimento micelial no tempo final $(\mathrm{mm})$;

$\mathrm{Vi}=$ medida do crescimento micelial no tempo inicial $(\mathrm{mm}) ;$

$\mathrm{Tf}=$ Tempo final (dias). 


\subsection{Análise Estatística}

Em todos os experimentos, os dados foram submetidos à análise de variância e as médias foram comparadas pelo teste de Tukey $(\rho<0,05)$ (Minitab, 2018).

\section{Resultados e Discussão}

A tabela 1 apresenta os resultados da velocidade média de crescimento radial (VCR) e a densidade micelial P. djamor. Em todos os meios de cultivo naturais e sintéticos foi observado o crescimento micelial radial. Os dados demonstraram que a VCR significativa foi determinada nos cultivos à base de tubérculos, SYA+YE $(11,26 \mathrm{~mm} / \mathrm{dia})$ e PYA+YE $(10,97 \mathrm{~mm} / \mathrm{dia})$. Em BDA+YE, SAB+YE e MEA+YE, o crescimento foi mais lento, com redução da VCR inferior em 9,77\%, 20,15\%, 20, 24\%, respectivamente, quando comparado ao crescimento em ágar Cará-de-Espinho (SYA+YE). A diferença no crescimento micelial em meios distintos, provavelmente seja devido à disponibilidade de diferentes fontes de carbono e outros nutrientes imprescindíveis para o crescimento de espécies de Pleurotus (Sardar et al., 2015). Esses dados sugerem que os tubérculos avaliados neste estudo são importantes reservas nutricionais e constituem uma alternativa viável como substratos para o crescimento in vitro de $P$. djamor.

Tabela 1. Média da velocidade do crescimento micelial in vitro e vigor micelial de $P$. djamor DPUA 1818 em meios naturais e sintéticos.

\begin{tabular}{lccc}
\hline \multicolumn{1}{c}{ Meios de cultivo } & $\begin{array}{c}\text { Velocidade do Crescimento } \\
(\mathrm{mm} / \text { dia) }\end{array}$ & Vigor Micelial & $\begin{array}{c}\text { Nota } \\
\text { (Critério Subjetivo) }\end{array}$ \\
\hline SYA+YE & $11,26 \pm 0,82^{\mathrm{a}}$ & Fracamente adensado & 1 \\
PYA+YE & $10,97 \pm 0,28^{\mathrm{a}}$ & Fracamente adensado & 1 \\
BDA+YE & $10,16 \pm 0,42^{\mathrm{b}}$ & Mediamente adensado & 2 \\
SAB+YE & $8,992 \pm 0,794^{\mathrm{c}}$ & Fortemente adensado & 3 \\
MEA+YE & $8,9833 \pm 0,1675^{\mathrm{c}}$ & Mediamente adensado & 2 \\
\hline
\end{tabular}

SYA+YE (ágar cará-de espinho + extrato de levedura), PYA+YE (ágar inhame roxo + extrato de levedura), BDA+YE (ágar batata dextrose + extrato de levedura), SAB+YE (ágar Sabouraud + extrato de levedura), MEA+YE (ágar extrato de malte + extrato de levedura). Médias que não compartilham a mesma letra são significativamente diferentes.

Fonte: Autores.

Na Figura 1 está demonstrada a velocidade do crescimento e a densidade do micélio com base no vigor micelial. Nos cultivos em ágar SAB+YE foi observado crescimento lento, mas formação de micélio fortemente adensado de $P$. djamor, propriedade que evidencia esse meio de cultura como promissor para o cultivo dessa espécie. Com exceção de ágar MEA+YE, predominou o crescimento micelial rápido. Em BDA+YE e MEA+YE a densidade micelial foi mediamente adensado e, fracamente adensado em SYA+YE e PYA+YE. Estudos demonstraram o desenvolvimento de micélio fortemente adensado de P. djamor e P. ostreatus nos cultivos em BDA+YE e BDA, respectivamente (Bumanlag, Kalaw, Dulay, \& Reyes, 2018; Fletcher, 2019). E para P. sapidus micélio mediamente adensado nos cultivos em ágar Sabouraud, dado que diverge do encontrado no presente estudo (Mahadevan \& Shanmugasundaram, 2018). Portanto, além de nutrientes, outros fatores como pH, temperatura e concentração do substrato também influenciam no crescimento e na densidade micelial das espécies de Pleurotus (Laursen, 2018; Toan \& Qui, 2020; Raman et al., 2021). 
Figura 1. Densidade micelial de $P$. djamor em diferentes meios de cultivo.

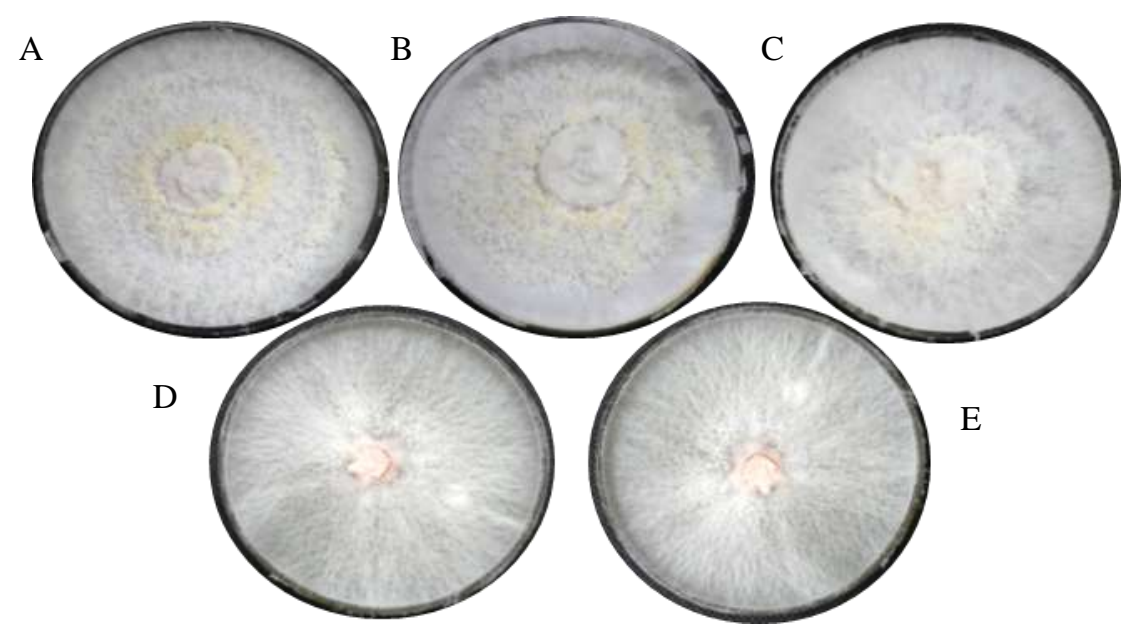

A- Ágar batata dextrose + extrato de levedura $(\mathrm{BDA}+\mathrm{YE})=$ mediamente adensado; B- Ágar extrato de malte + extrato de levedura $(\mathrm{MEA}+\mathrm{YE})=$ mediamente adensado; $\mathrm{C}$ - Ágar Sabouraud + extrato de levedura $(\mathrm{SAB}+\mathrm{YE})=$ fortemente adensado; D- Ágar cará-de-espinho + extrato de levedura $(\mathrm{SYA}+\mathrm{YE})=$ fracamente adensado; E- Ágar inhame-roxo + extrato de levedura $(\mathrm{PYA}+\mathrm{YE})=$ fracamente adensado. Fonte: Autores.

A Tabela 2 demonstra a atividade de proteases determinada nos meios de cultura (ágar BDA+YE, MEA+YE, $\mathrm{SAB}+\mathrm{YE}$, PYA+YE e SYA+YE) usados para crescimento radial de $P$. djamor. Nos cinco meios de cultivo a média do diâmetro do halo correspondeu a $12,78 \mathrm{~mm}$ e o valor de atividade significativa foi determinado em BDA+YE (17,7 mm), MEA+YE (17,6 mm) e SAB+YE (17,0 mm). Nos meios naturais, PYA+YE e SYA+YE, a atividade das proteases foi inferior $17,52 \%$ e 26,42\%, respectivamente. Nos estudos realizados por Sabri et al. (2020), P. ostreatus também excretou proteases em BDA+ folhas de Stevia rebaudian e atividade determinada em ágar leite, contudo o diâmetro do halo foi de aproximadamente $15 \mathrm{~mm}$

Tabela 2. Média de atividade de proteases de $P$. djamor utilizando meios de cultura sólidos e naturais.

\begin{tabular}{lc}
\hline \multicolumn{1}{c}{ Meios de cultivo } & Atividade de Proteases [halo (mm)] \\
\hline Meios Sintéticos & $17,7 \pm 0,04^{\mathrm{a}}$ \\
BDA+YE & $17,6 \pm 0,02^{\mathrm{ab}}$ \\
MEA+YE & $17,0 \pm 0,07^{\mathrm{abc}}$ \\
SAB+YE & \\
Meios Naturais & $14,6 \pm 0,09^{\mathrm{bc}}$ \\
PYA+YE & $14,0 \pm 0,09^{\mathrm{c}}$ \\
SYA+YE & \\
\hline
\end{tabular}

SYA+YE (Ágar cará-de espinho + extrato de levedura), PYA+YE (Ágar inhame roxo + extrato de levedura), BDA+YE (ágar batata dextrose + extrato de levedura), SAB+YE (ágar Sabouraud + extrato de levedura), MEA+YE (ágar extrato de malte + extrato de levedura). Médias que não compartilham a mesma letra são significativamente diferentes.

Fonte: Autores.

O crescimento micelial de $P$. djamor em resíduos lignocelulósicos da fruticultura amazônica foi positivo em $75 \%$ das mistura de substratos (Tabela 3). A VCM significativa foi observada em SAW+WB (0,37 cm/dia), CE+WB (0,37 cm/dia), $\mathrm{CE}+\mathrm{RB}(0,30 \mathrm{~cm} / \mathrm{dia})$ e AS+RB $(0,23 \mathrm{~cm} / \mathrm{dia})$. Nos cultivos em SAW+RB e AS+WB, o crescimento foi inferior $37,83 \%(0,23$ $\mathrm{cm} /$ dia) e 48,64\% (0,19 cm/dia), respectivamente, comparado aos resultados registrados em SAW+WB e CE+WB. A forma micelial de $P$. djamor não foi observada em PE+RB e PE+WB. Ademais, nos cultivos em exocarpo de cupuaçu (CE+WB e 
CE+RB) $P$. djamor desenvolveu micélio fortemente adensado. E nos cultivos à base de açaí (AS+WB e AS+RB) e serragem (SAW+WB e SAW+RB) a o micélio foi classificada como mediamente adensado e fracamente adensado, respectivamente. Nos experimentos realizados por Palheta et al. (2011), os resultados indicaram que exocarpo de cupuaçu favoreceu o crescimento de P. ostreatus e P. florida.

Tabela 3. Média de velocidade de crescimento vertical em resíduos lignocelulósicos e vigor micelial de Pleurotus djamor.

\begin{tabular}{lccc}
\hline \multicolumn{1}{c}{ Tratamento } & VCM $(\mathbf{c m} / \mathbf{d i a})$ & Densidade & Nota \\
\hline SAW+WB & $0,37 \pm 0,37^{\mathrm{a}}$ & Fracamente adensado & 3 \\
CE+WB & $0,37 \pm 0,01^{\mathrm{a}}$ & Fortemente adensado & 3 \\
CE+RB & $0,30 \pm 0,01^{\mathrm{ab}}$ & Fortemente adensado & 2 \\
AS+RB & $0,23 \pm 0,01^{\mathrm{ab}}$ & Mediamente adensado & 1 \\
SAW+RB & $0,23 \pm 0,12^{\mathrm{b}}$ & Fracamente adensado & 2 \\
AS+WB & $0,19 \pm 0,01^{\mathrm{b}}$ & Mediamente adensado & ND \\
PE+RB & ND & ND & ND \\
PE+WB & ND & ND & \\
\hline
\end{tabular}

$\mathrm{SAW}+\mathrm{WB}=$ serragem + farelo de trigo; $\mathrm{CE}+\mathrm{WB}=$ exocarpo de cupuaçu + farelo de trigo; $\mathrm{CE}+\mathrm{RB}=$ exocarpo de cupuaçu + farelo de arroz; $\mathrm{AS}+\mathrm{RB}=$ semente de açaí + farelo de arroz; $\mathrm{SAW}+\mathrm{RB}=$ serragem + farelo de arroz; $\mathrm{PE}+\mathrm{RB}=$ exocarpo de abacaxi + farelo de arroz; $\mathrm{PE}+\mathrm{WB}=$ exocarpo de abacaxi + farelo de trigo; $\mathrm{ND}=$ não determinado; Médias que não compartilham a mesma letra são significativamente diferentes.

Fonte: Autores.

Dados da literatura demonstram que o gênero Pleurotus demonstra grande preferência por resíduos lignocelulósicos, substratos ricos em celulose, hemicelulose e lignina que estimulam a síntese de enzimas degradadoras essenciais para o crescimento dos cogumelos (Salmones, 2018; Singh \& Singh, 2018). Assim como as demais espécies do gênero, Pleurotus djamor também apresenta a habilidade para degradar lignina e polímeros presentes na parede celular vegetal, capacidade comprovada ao utilizar fibra de coco (Theradinami, Thangeshwari, Arulsamy, \& Parthasarathy, 2019). Resíduos agroindustriais influenciam significativamente no crescimento, na qualidade do micélio e na formação de basidiomas. A estrutura, a composição desses substratos e a relação carbono/nitrogênio provavelmente fornecem condições físicas e nutricionais, parâmetros favoráveis para o desenvolvimento do micélio e reprodução das diversas espécies de cogumelos (Salmones, 2018; Osunde, Olayinka, Fashina, \& Torimiro, 2019; Toan \& Qui, 2018; Wu et al., 2019).

\section{Conclusão}

O meio de cultivo influencia no crescimento e na produção de enzimas proteolíticas por Pleurotus djamor. Ágar Sabouraud+extrato de levedura (SAB+YE) é o meio sintético promissor para desenvolvimento da densidade micelial máxima. Entre os resíduos lignocelulolíticos, a mistura formulada com exocarpo de cupuaçu com farelo de arroz (CE+RB) ou farelo de trigo (CE+WB) estimulou o crescimento, assim como, a forte densidade micelial. Pleurotus djamor sintetiza proteases tanto em meios de cultura sintéticos como em substratos naturais. Os meios de cultivo à base de tubérculo amazônicos constituem uma alternativa tecnológica sustentável e ecoamigável para o crescimento e biossíntese de proteases por P. djamor.

\section{Agradecimentos}

À Coordenação de Aperfeiçoamento de Pessoal de Nível Superior (CAPES) e à Universidade Federal do Amazonas (UFAM), pelo apoio técnico, científico e financeiro. 


\section{Referências}

Balan, V., Munafo, J. P. J., Pattathill, S., Merritt, B. B., Venketachalam, S. \& Ng, W. (2018). Protocols to Evaluate the Nutritional and Potential Health Benefits of Edible Mushrooms. Current Biotechnology, 7(1), 34-58.

Barh, A., Sharma, V. P., Annepu, S. K., Kamal, S., Sharma, S., \& Bhatt P. (2019). Genetic improvement in Pleurotus (oyster mushroom): a review. 3 Biotech, 9(322), 1-14.

Benmrad, M. O., Mechri, S., Jaouadi, N. Z., Elhoul, M. B., Rekik, H., Sayadi, S., Bejar, S., Kechaou, N., \& Jaouadi, B. (2019). Purification and Biochemical Characterization of a Novel Thermostable Protease from the Oyster Mushroom Pleurotus sajor-caju Strain CTM10057 with Industrial Interest. BMC Biotechnology, 19(43), 1-18.

Bumanlag, C. P. B., Kalaw, S. P., Dulay, R. M. R., \& Reyes, R. G. (2018). Optimum Conditions for Mycelial Growth and Basidiocarp Production of Pleurotus djamour on Corn-based Media. International Journal of Biology, Pharmacy and Allied Sciences, 7(4), 558-575.

Castillo, T. A. (2009). Caracterização fisiológica, produção de biocompostos e biomassa em substrato agroflorestal amazônico de Pleurotus e Lentinus. 151 f. Tese (Doutorado em Biotecnologia) - Universidade Federal do Amazonas, Manaus.

Carrasco-González, J. A., Serna-Saldívar, S. O., \& Gutiérrez-Uribe, J. A. (2017). Nutritional attributes of Pleurotus mushroom. Journal of Food Composition and Analysis, 58, 69-81.

Devi, S. K., Prabhu, N., Monika, S., Swapna, N. M., Vaishali, S., \& Gajendran, T. (2020). Sequestration and purification of essential enzyme from Pleurotus florida compost waste and its application studies. Journal of Applied Biology \& Biotechnology, 8(1), 64-68.

Fletcher, I. A. (2019). Effect of Temperature and Growth Media on Mycelium Growth of Pleurotus ostreatus and Ganoderma Lucidum Strains. Cohesive journal of microbiology and infectious disease, 2(5), 1-5.

Fonseca, R. B. T., Silva, T. A., Alecrim, M. M., Cruz, R. F., Filho \& Teixeira, M. F. S. (2015). Cultivation and nutritional studies of an edible mushroom from North Brazil. African Journal of Microbiology Research, 9(30), 1814-1822.

Israel, C. M. (2005). Utilização do resíduo do processamento do palmiteiro para a produção de enzimas hidrolíticas por fungos do gênero Polyporus. Dissertação (Mestrado em Engenharia Ambiental) - Centro de Ciências Tecnológicas, Universidade Regional de Blumenau, Blumenau. 136 f.

Jegadeesh, R., Lakshmanan, H., Kab-Yeul, J., Sabaratnam, V., \& Raaman, N. (2018). Cultivation of Pink Oyster mushroom Pleurotus djamor var. roseus on various agro-residues by low cost technique. Journal of Mycopathological Research, 53(3), 213-220.

Laursen, A. (2018). The Effect of Different Nitrogen Sources on Mycelial Growth of Oyster Mushroom, Pleurotus ostreatus. Online publication: http://stud.epsilon.slu.se, p. 1-60.

Machado, A. R. G., Teixeira, M. F.S., Kirsch, L. S., Campelo, M. C. L., \& Oliveira, I. M. A. (2016). Nutritional value and proteases of Lentinus citrinus produced by solid state fermentation of lignocellulosic waste from tropical region. Saudi Journal of Biological Sciences, 23(5), 621-627.

Mahadevan, K., \& Shanmugasundaram, K. (2018). Comparative effect of different culture media on mycelial growth performance of Pleurotus sapidus. Journal of Pharmacognosy and Phytochemistry, 7(4), 874-878.

Marino, R. H.; Abreu, L. D.; Mesquita, J. B., \& Ribeiro, G. T. (2008). Crescimento e cultivo de diferentes isolados de Pleurotus ostreatus (Jacq.: Fr.) Kummer em serragem da casca de coco. Arquivos do Instituto Biológico, 75(1), 29-36.

Minitab, 2017. Minitab statistical software. LEAD Technologies, Inc. Version 18.0.

Oropeza-Guerrero, M. P., Santos-Sánchez, N. F., Salas-Coronado, R.; Valadez-Blanco, R.; Hernández-Carlos, B., \& Guadarrama-Mendoza, P. C. (2018). Productivity and Antioxidant Activity of Wild, Reconstituted, and Hybrid Strains of the Pink Oyster Mushroom, Pleurotus djamor (Agaricomycetes), from Mexico. International Journal of Medicinal Mushrooms, 20(7), 607-621.

Osunde, O. M., Olayinka, A., Fashina, C. D., \& Torimiro, N. (2019). Effect of Carbon-Nitrogen Ratios of Lignocellulosic Substrates on the Yield of Mushroom (Pleurotus pulmonarius). Open Access Library Journal, 6, 1-8.

Palheta, R. A., Vieira, J. N., Neves, K. C. S., \& Teixeira, M. F. S. (2011). Crescimento micelial vertical de duas espécies de Pleurotus em resíduo agroindustrial da Amazônia utilizando planejamento fatorial. Caderno de Pesquisa Série Biologia, 23(3), 52-60.

Putzke, J., \& Putzke M. T. L. (2019) Cogumelos (fungos Agaricales) no Brasil - Ordens Boletales (Boletaceae, Paxillaceae), Polypolares (Lentinaceae/ Pleurotaceae, Polyporaceae). Russalales (Russaleceae) e Agaricales (Cortrinariaceae, Inocybaceae, Pluteaceae e Strophariaceae), São Gabriel: e-book, 380 f.

Ragasa, C., Tan, M. C. S., Ting, J., Reyes, R. G., Brkljača, R., \& Urban, S. (2016). Chemical constituents of Pleurotus djamor. Der Pharma Chemica, $8(2), 343-346$

Raman, J., Jang, K. Y., Oh, Y. L., Oh, M., Im, J. H., Lakshmanan, H., \& Sabaratnam, V. (2021). Cultivation and nutritional value of prominent Pleurotus spp.: An overview. Mycobiology, 49(1), 1-14.

Raman, J., Hariprasath, L., Jang, K. Y., Vikineswary, S. A., \& Nanjian, R. (2018). Cultivation of Pink Oyster mushroom Pleurotus djamor var. roseus on various agro-residues by low-cost technique. J. Mycopathol. Res., 56(3), 213-220.

Sabri, M. A., Shafiq, A., \& Chechan, R A. (2020). Production of Spawn with High Quality from Novel Iraqi Strains of Edible Mushrooms. Plant Archives, $20(1), 2135-2142$

Sardar, H., Ali, M. A., Ayyub, C. M., Ahmad, R. (2015). Effects of Different Culture Media, Temperature and pH Levels on the Growth of Wild and Exotic 
Research, Society and Development, v. 10, n. 3, e31810313385, 2021

(CC BY 4.0) | ISSN 2525-3409 | DOI: http://dx.doi.org/10.33448/rsd-v10i3.13385

Pleurotus Species. Pakistan Journal of Phytopathology, 27(2),139-145.

Salmones, D. (2018). Pleurotus djamor, un hongo con potencial aplicación biotecnológica para el neotrópico. Scientia Fungorum, 46, 73-85.

Satpal, S., Gopal, S., N, R. S., Ankit, K., Bhanu, P., Priyanka, B., \& Kumar, R. (2017). Effect of Different Substrates on the Growth and Yield of Oyster Mushrooms (Pleurotus djamor). Research Article, 9(4), 3721-3723.

Sekan, A. S., Myronycheva, O. S., Karlsson, O., Grygansky, A. P., \& Blume, Y. (2019) Green potential of Pleurotus spp. in biotechnology. PeerJ, 1-21.

Singh, S., \& Singh G. (2018). Effect of Environment Conditions (pH , Temperature and Media) on Radial Growth of Oyster Mushroom (Pleurotus djamor). HortFlora Research Spectrum, 5(4), 7-11.

Souza, R. A. T., Fonseca, T. R. B., Kirsch, L. S., Silva, L. S. C., Alecrim, M. M., Filho, R. F. C., \& Texeira, M. F. S. (2016). Nutritional composition of bioproducts generated from semi-solid fermentation of pineapple peel by edible mushrooms. African Journal of Biotechnology, 15(12), $451-457$.

Sudha, G., Janardhanan, A., Moorthy, A., Chinnasamy, M., Gunasekaran, S., Thimmaraju, A., \& Gopalan, J. (2016). Comparative Study on the Antioxidant Activity of Methanolic and Aqueous Extracts from the Fruiting Bodies of an Edible Mushroom Pleurotus djamor. Food Sci. Biotechnol. 25(2), $371-377$.

Teixeira, M. F. S., Silva, T. A., Palheta, R. A., Carneiro, A. L. B., \& Ataíde, H. M. (2011). Fungos da Amazonia: uma riqueza inexplorada (Aplicações Biotecnológicas). Manaus: Edua.

Theradinami, M., Thangeshwari, S., Arulsamy, M., \& Parthasarathy, S. (2019). Composted Coirpith using Edible Fungi (Pleurotus spp.) for the Management of Rice Sheath Blight and Sheath Rot. Research Journal of Agricultural Sciences, 10(3), 521-525.

Toan, N. V., \& Qui, L. N. M. (2018). Preparation and Improved Quality Production of Flour and the Made Biscuits from Shitake Mushroom (Lentinus edodes). Clinical Journal of Nutrition and Dietetics, 1(1), 1-9.

Wu, N., Tian, F., Moodley, O., Song, B., Jia, C., Ye, J., LV, R., Qin, Z., \& Li, C. (2019). Optimization of agro-residues as substrates for Pleurotus pulmonarius production. AMB Expr, 9, 1-9. 